\title{
An experimental model of oculorespiratory reflex
}

\author{
A K Khurana, Indu Khurana, R N Yadav, P I Singh, K K Gombar, B K Ahluwalia
}

Medical College, Rohtak, Haryana, India

Department of Ophthalmology

A K Khurana

R N Yadav

B K Ahluwalia

Department of

Physiology

I Khurana

P I Singh

Department of

Anaesthesiology

K K Gombar

Correspondence to:

Dr A K Khurana, 34/9 J,

Medical Enclave, Rohtak

124001, Haryana, India.

Accepted for publication

11 July 1991

\section{Abstract}

An experimental study of the oculorespiratory reflex (ORR) was conducted on 20 albino rabbits using a square wave (SW) type of stimulus. The ORR could be elicited in $100 \%$ of animals. The medial rectus was observed to be most reflexogenic for ORR. The frequency and pattern of ORR was not affected by bilateral vagotomy, intravenous atropine or glycopyrrolate, but could be completely abolished by retrobular block.

The oculorespiratory reflex (ORR), which manifests as slowing of respiratory rate and/or respiratory rhythm changes due to pressure or manipulation of the eye, was first described by Aschner ${ }^{1}$ in rabbits. It was later elicited by evoking pressure on human eyes. ${ }^{2}$ Since then little attention has been paid to it till a recent article in which Blanc et $a l^{3}$ reported that ORR is a frequent and potentially dangerous occurrence

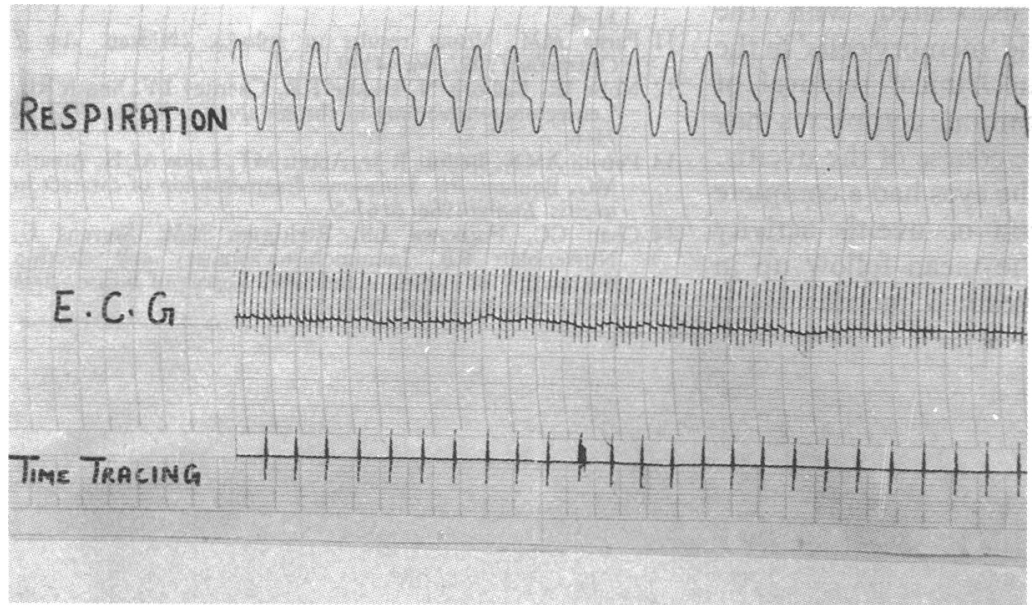

Figure 1 Basal record of respiration and electrocardiograph.

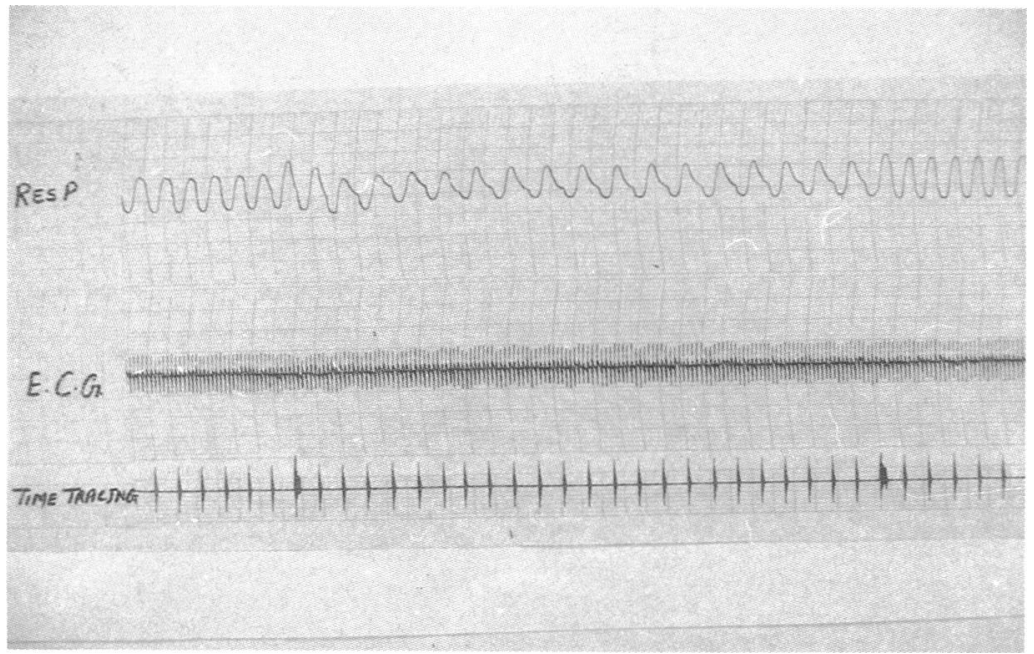

Figure 2 Positive ORR. Pattern I: slowing of respiration.
Table 1 Patterns of oculorespiratory reflex

\begin{tabular}{lcc}
\hline Pattern of oculorespiratory reflex & $\begin{array}{l}\text { No. of } \\
\text { rabbits }\end{array}$ & $\%$ \\
\hline 1 Slowing of respiration only & 6 & 30 \\
2 Apnoea followed by irregular respiration & 7 & 35 \\
3 Irregular respiration followed by rapid shallow & 7 & 35 \\
$\begin{array}{l}\text { breathing } \\
\text { Total }\end{array}$ & 20 & 100 \\
\hline
\end{tabular}

during extraocular muscle traction. Therefore the present experimental work was planned to study the different aspects of occurrence and prevention of the ORR.

\section{Material and methods}

Experiments were carried out on 20 albino rabbits of either sex weighing between 1 and $2 \mathrm{~kg}$. Overnight fasting rabbits were anaesthetised with intravenous pentobarbitone $(40 \mathrm{mg} / \mathrm{kg}$ body weight). Tracheostomy was performed for endotracheal intubation. The vagi were separated in the cervical region. The femoral vein of one side was cannulated for intermittent injection of anaesthetic and infusion of drugs. Respiration was recorded from a tracheal cannula by a transducer on Polyrite (Inco). The electrocardiogram was recorded by needle electrodes.

All four rectus muscles - medial (MR), lateral (LR), superior (SR), and inferior (IR) were exposed by a gently performed perilimbal peritomy and a silk suture loop was passed under each muscle. A silk suture with wire hooks on both ends was passed over a pulley fixed on a stand. One hook was engaged in the silk suture loop under the muscle tendon and on the other weights were attached.

In each rabbit, after taking the basal recording of respiration and ECG, traction with a $150 \mathrm{~g}$ weight was applied by a square wave (SW) type of stimulus (acute traction sustained for a minimal period of 20 seconds followed by acute release) to medial rectus and changes in heart and respiratory rate as well as rhythm were recorded. The procedure was repeated for lateral, superior, and inferior recti after a pause of 3 minutes. For further study the 20 rabbits were divided into four groups of five rabbits each. In group I, after taking the basal recordings, bilateral vagotomy was performed in the cervical region and its effects on ORR were elicited by a SW stimulus to the medial rectus only. Similarly effects of intravenous atropine (15 $\mu \mathrm{g} / \mathrm{kg}$ body weight), intravenous glycopyrrolate $(7 \cdot 5 \mu \mathrm{g} / \mathrm{kg}$ body weight), and retrobulbar block (after 10 minutes of injection of $2 \mathrm{ml}$ of $2 \%$ xylocaine) were elicited in rabbits in groups II, III, and IV, respectively.

A fall in respiratory rate of $10 \%$ or more and/or respiratory rhythm changes and/or development of shallow respiratory movements during muscle 


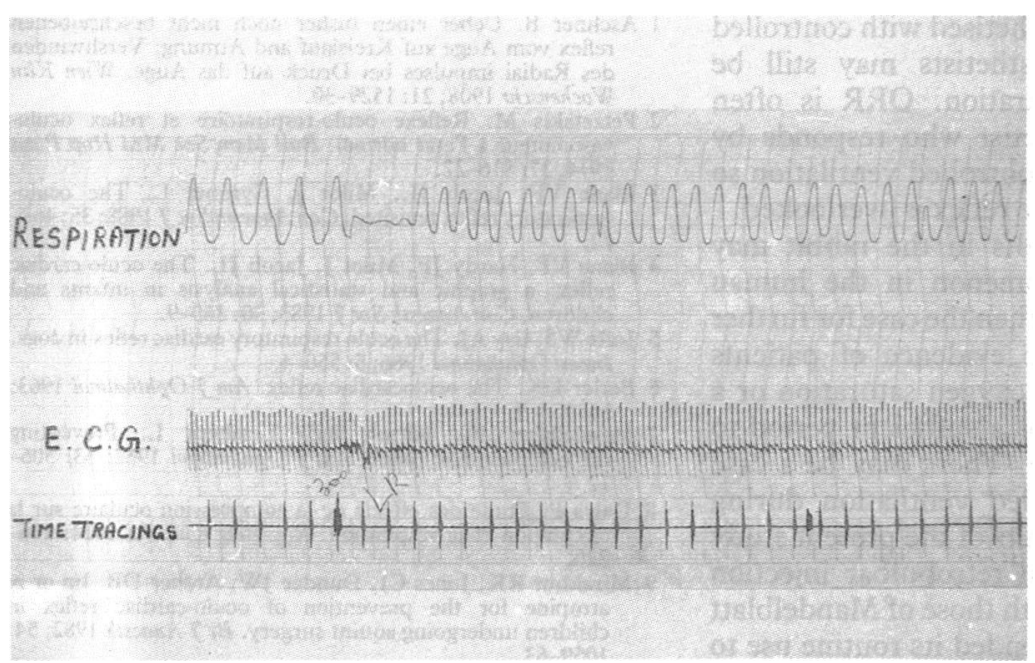

Figure 3 Positive ORR. Pattern II: apnoea followed by irregular respiration.

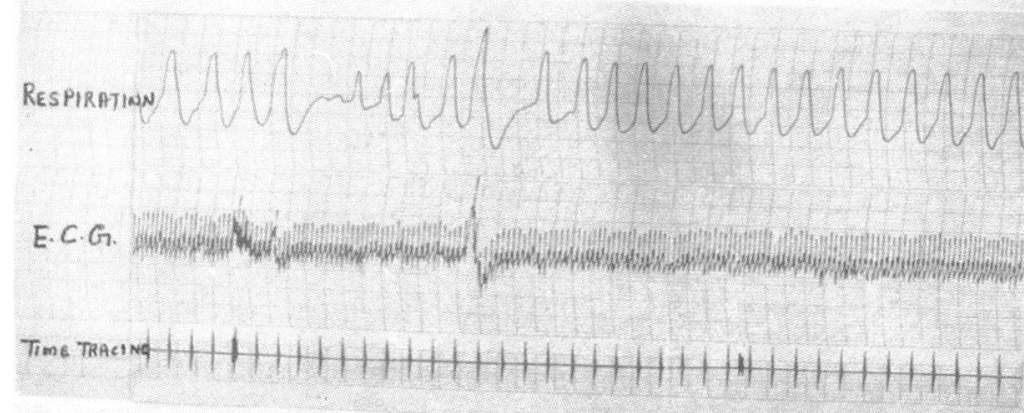

Figure 4 Positive ORR. Pattern III: irregular respiration followed by rapid shallow breathing.

traction was the criterion considered for positive ORR. $^{3}$

\section{Results}

All 20 animals (100\%) exhibited positive ORR on extraocular muscle traction. The frequency of ORR on stretching lateral, superior, and inferior rectus muscles was identical ( $90 \%$ each), while the medial rectus was observed to be more sensitive $(100 \%)$. As shown in Table 1 three different patterns of ORR were observed in this experimental study. Slowing of respiratory rate was observed in six (30\%), apnoea followed by irregular respiration in seven (35\%) and irregular respiration followed by rapid shallow breathing in seven (35\%) animals. The basal recordings and the three patterns of ORR observed are shown in Figs 1 to 4. Occurrence of ORR was observed in $100 \%$ of animals after vagotomy and intravenous atropine as well as glycopyrrolate; while none of the animals demonstrated positive ORR after retrobulbar block (Table 2).

\section{Discussion}

The SW stimulus was chosen in the present experimental model as it is considered highly reflexogenic. ${ }^{4}$ The oculorespiratory reflex could be elicited in all the animals studied. Our results are similar to those of Blanc et $a l^{3}$ who noted ORR in $100 \%$ of the cases studied using an SW traction of $200-250 \mathrm{~g}$ lasting for $10-15$ seconds. Joffe and Gay ${ }^{5}$ also observed ORR in all the cases by uniocular or binocular manual pressure on the eyeball.

In the present study the medial rectus was observed to be most sensitive, as $100 \%$ of the muscles on stretching demonstrated positive ORR in comparison to $90 \%$ each with $L R, S R$, and IR. In the available literature we could find no study relating the incidence of ORR with the muscle stretched. However higher sensitivity of the $M R$ as regards occurrence of oculocardiac reflex (OCR) is well documented in the literature. ${ }^{67}$

We have observed three different patterns of ORR (Table 2, Figs 2 to 4). Blanc et al $^{3}$ reported slowing of respiration, and/or shallow respiratory movements in each patient and apnoea of 20 seconds duration in only one patient. Joffe and Gay ${ }^{5}$ noticed expiratory pause by uniocular or binocular manual pressure and apnoea, and respiratory arrhythmia occasionally leading to irregular respiratory arrest by intraorbital and intracranial stimulation.

In the present study no effect of vagotomy, atropine, or glycopyrrolate was seen on the ORR, which could be completely abolished by retrobulbar block (Table 2 ). Delva ${ }^{8}$ also could not prevent ORR after bilateral vagotomy and section of the spinal cord at the level of the seventh cervical vertebra (phrenic nerve intact) on dogs. Patizetakis ${ }^{2}$ noted a similar response and reported that atropine does not change the incidence of ORR. However Delva ${ }^{8}$ like Joffe and $\mathrm{Gay}^{5}$ demonstrated that atropine enhances the ORR. In the available literature we could trace no study on the effects of glycopyrrolate and retrobulbar block on ORR. Our observations clearly reflect that the efferent pathway of ORR must be different from that of OCR, as the latter could be abolished by vagotomy,${ }^{8}$ intravenous atropine,${ }^{4}$ and glycopyrolate. ${ }^{9}$ Therefore it seems that OCR and ORR are not interrelated but are independent of each other. However Blanc et $a l^{3}$ have reported a high incidence of OCR in patients with hypoxia. Hence it is tempting to speculate that ORR by producing hypoxia might be increasing the incidence of OCR.

The results of the present study fully corroborate the views of Blanc et $a l^{3}$ that ORR is a frequent and potentially dangerous occurrence during extraocular muscle traction. However this reflex is not widely recognised by ophthalmologists or anaesthesiologists. This phenomenon may not be recognised in the centres where

Table 2 Frequency of oculorespiratory reflex before and after treatment in different groups

\begin{tabular}{llll}
\hline & & \multicolumn{2}{l}{$\begin{array}{l}\text { Rabbits with positive } \\
\text { ORR (\%) }\end{array}$} \\
\cline { 3 - 4 } Group & $\begin{array}{l}\text { Total no. } \\
\text { of rabbits }\end{array}$ & $\begin{array}{l}\text { Before } \\
\text { treatment }\end{array}$ & $\begin{array}{l}\text { After } \\
\text { treatment }\end{array}$ \\
\hline Group I (vagotomy) & 5 & $5(100)$ & $5(100)$ \\
Group II (atropine) & 5 & $5(100)$ & $5(100)$ \\
Group III (glycopyrrolate) & 5 & $5(100)$ & $5(100)$ \\
Group IV (retrobulbar block) & 5 & $5(100)$ & 0 \\
\hline
\end{tabular}


squint patients are anaesthetised with controlled ventilation. Many anaesthetists may still be using spontaneous respiration. ORR is often ignored by the anaesthetist who responds by introducing assisted or controlled ventilation so that the significance of the reflex is overlooked.

These significant results in the rabbit may suggest a similar phenomenon in the human patient and would strengthen the case for further research. There is little evidence of patients having suffered a fall in oxygen saturation or a rise in carbon dioxide for a sufficient period to have clinical significance. There may be a case for encouraging controlled ventilation during squint surgery. ${ }^{3}$ The results of the present study in preventing ORR with retrobulbar injection are in close agreement with those of Mandelblatt et $a l,{ }^{7}$ who have recommended its routine use to block the OCR in all cases of local or general ophthalmic surgery, and also agrees with the results of Kirsch et al. ${ }^{10}$
1 Aschner B. Ueber einen bisher noch nicht beschreibenen reflex vom Auge auf Kreislauf and Atmung: Vershwinden des Radial impulses bei Druck auf das Auge. Wien Klin Wochenschr 1908; 21: 1529-30.

2 Petzetakis $M$. Reflexe oculo-respiratoire et reflex oculovasomoteur a l'etat normal. Bull Mem Soc Med Hop Paris 1914; 37: 816-22.

3 Blanc VF, Jacob JL, Milot J, Cyrnnel L. The oculorespiratory reflex revisited. Can Anaesth Soc F 1988; 35: 46872 .

4 Blanc VF, Hardy JF, Milot J, Jacob JL. The oculo-cardiac reflex: a graphic and statistical analysis in infants and reflex: a graphic and statistical analysis in
children. Can Anaesth Soc $\mathcal{F} 1983 ; 30: 360-9$.

5 Joffe WS, Gay AJ. The oculo respiratory cardiac reflex in dogs. Invest Ophthalmol 1966; 5: 550-4.

6 Berler DK. The oculocardiac reflex. Am $\mathcal{F}$ Ophthalmol 1963;

7 56: $954-9$. . FI, Kirsch RE, Lemberg L. Preventing the oculo-cardiac reflex. Am f Ophthalmol 1962; 53: 50612.

8 Delva P. Etude des effects de la compression oculaire sur la circulation et la respiration. Roy Belg Clin Sci 1914: 196220.

9 Mirakhur RK, Jones CJ, Dundee JW, Archer DB. Im or iv atropine for the prevention of oculo-cardiac reflex in
children undergoing squint surgery. $B r \mathcal{F}$ Anaesth 1982; 54: children ung-63.

10 Kirsch RE, Samec P, Kugel V, Axelord S. Electrocardiographic changes during ocular surgery and their prevention graphic changes during ocular surgery and their prevention
by retrobulbar injection. AMA Arch Ophthalmol 1957; 58: 348-56. 